\title{
Naturalised modal epistemology and quasi-realism
}

\author{
Michael Omoge \\ Philosophy, University of the Western Cape, Cape Town, South Africa \\ mykhology@gmail.com
}

\begin{abstract}
Given quasi-realism, the claim is that any attempt to naturalise modal epistemology would leave out absolute necessity. The reason, according to Simon Blackburn, is that we cannot offer an empirical psychological explanation for why we take any truth to be absolutely necessary, lest we lose any right to regard it as absolutely necessary. In this article, I argue that not only can we offer such an explanation, but also that the explanation will not come with a forfeiture of the involved necessity. Using "squaring the circle" as evidence, I show that, contrary to quasi-realism, absolute necessity will not be left out in attempts to naturalise modal epistemology.
\end{abstract}

\section{Introduction}

For a considerable period, modal epistemology, the study of our knowledge of possibility and necessity, was done rationalistically, i.e. independently of the empirical sciences that study our experiences of modality. Following Quine's (1969) now famous Epistemology Naturalized, ${ }^{1}$ however, we have been called to take findings from those sciences seriously when doing modal epistemology, i.e. we have been called to naturalise modal epistemology (Nolan 2017a). Elsewhere, (Omoge 2021), I tried to respond to this call. I argued that by scrutinising the psychology of imagination, we can get a better handle on what it takes to use imagination to make metaphysical modal judgments. In essence, I offered a naturalistic epistemological account of metaphysical modality by way of psychologising imagination.

However, since many philosophers take metaphysical modality to be absolute, i.e. modality in the widest sense or modality without qualification (Clarke-Doane 2019), and given Simon Blackburn's quasi-realism (1984; 1993), my imagination-based, psychologically² naturalised, modal epistemological account seems to face one significant problem. According to Blackburn (1993, 70), any epistemological account of absolute necessity that operates by psychologising imagination would explain away the involved necessity:

we cannot explain naturalistically our own failure to see what it would be for [an absolutely necessary falsehood] to be true. When we can see how, if [it] were true...we release it from impossibility. It does not deserve ruling out any more.

If so, and since some metaphysical necessities, e.g. logical (modus ponens) and arithmetical $(1+1=$ 2) ones, are archetypical examples of absolute necessity, then my imagination-based psychological analysis of metaphysical modality can be said to have inadvertently jeopardised the absoluteness of metaphysical modality.

In this article, I argue against Blackburn's view that absolute necessity is antinaturalistic. In the second section, I explain why he holds this view. In the third section, I say more about some unclear aspects of his arguments, clarifying how I read him on those occasions. In the fourth section, I

1 Post-Quine, naturalism has been divided into at least metaphysical and methodological. Naturalism is metaphysical if philosophical questions are taken to be scientific ones, but it is methodological if the scientific method (using "scientific method" as an umbrella term to cover behavioural, natural, and human sciences) and/or scientific findings are taken as instrumental to philosophical analyses. See, for example, Papineau (2009) for a discussion. See also n. 4.

2 Naturalistic explanations need not be psychological, however. 
consider Shaun Nichols' (2006) response to Blackburn, arguing that even though he addresses one important aspect of Blackburn's concerns, he is silent where it matters most - whether once we can naturalistically explain why we take absolute necessities to be absolutely necessary, they cease to be absolutely necessary. Consequently, in the fifth section, I argue that "squaring the circle" is evidence that they do not: we can naturalistically explain why we take it to be absolutely impossible, and we do not thereby lose our right to regard it as absolutely impossible. In the sixth section, I address a possible quasi-realistic objection, and then conclude.

For clarity's sake, and because I will bring other kinds of necessity as we progress, I will retain speaking in terms of "absolute necessity", and not shorten it to "necessity".

\section{Blackburn on the antinaturalistic nature of absolute necessity}

Over the years, Blackburn has pushed for a project he calls quasi-realism, which he claims offers plausible treatments of a range of philosophical topics. One motivation for the project is that both realism and antirealism fail to correctly account for knowledge and truth. As he explains it, realism holds that knowledge and truth are grounded in an extra-natural realm of facts, whereas antirealism denies such a realm, encourages us to feel comfortable in claiming knowledge and truth as natural, but fails to tell us how to find them natural (Blackburn 1993). This failure of antirealism, Blackburn argues, leaves the semantic machinery of realism enticing, such that rejecting the machinery alongside the extra-natural realm of facts that realism postulates is like throwing the baby out with the bath water.

The way out, in his view, is a midway between realism and antirealism:

This result accords with what I call "quasi-realism", for it is another respect in which someone who approves of the anti-realist instinct over the priority of truth or virtue still ends up with the very thoughts that the realist took for his own (Blackburn 1993, 48).

In sum, quasi-realism is this midway between realism and anti-realism. Quasi-realism, therefore, asks

broadly anthropological questions: How are we to understand the roles and functions of the behaviour [or concept] in question, in the lives of the creatures concerned? What is its practical significance? Whence its genealogy? (Macarthur and Price 2007, 95).

By answering these questions, quasi-realism, Blackburn says, would yield empirical psychological explanations of our judgements in those situations.

Applying this quasi-realistic project to modality yields the stance that absolute necessity is antinaturalistic, in that (the blocks that issue) our judgments of absolute necessity become empirically psychologically unexplainable. According to him, this is because when we run modality through the anthropological questions that quasi-realism asks, as above, we see that the whole point of modalising is to vary our beliefs with circumstance, where "variation of beliefs with circumstance" involves making sense of the constant changes in our knowledge as we interact with others and with the world. Hence, Blackburn $(1993,66)$ says that "naturalized epistemology is largely a study of the variation of belief with circumstance". In his view, modalising helps us to do this and, because doing so was/is beneficial to our social and cognitive life, we have evolved to effortlessly and non-collusively modalise. This, according to him, is why we modalise. To be clear then, his concern is not with offering a naturalised epistemology of absolute necessity, but with one particular way - the psychological approach - of giving such an epistemology (see Omoge 2021). For him, psychologising why we absolutely modalise cannot/must not succeed. Let me expatiate.

In Blackburn's $(1993,66)$ view, psychologically explaining modalising involves making something of, which he defines thus:

Here "make something of" will include being able to explain how such a way of thought might arise, knowing how it might be rectified, understanding the practices of those whose thought it is, and so on.

Ultimately, "make something of" explains why he thinks absolute necessity is antinaturalistic in 
that it clarifies which modal commitments cannot be run through the anthropological questions that quasi-realism asks. For instance, we cannot answer whence comes the genealogy of $1+1=3$ because

[s]eeing it like that would require thinking the other side of the boundary: understanding how it might be, for instance, that although it is compulsory for us to use classical arithmetic, with a different cast of mind it might have been compulsory to use another arithmetic. And this we cannot do (Blackburn 1993, 72).

Since he says naturalised epistemology consists largely in varying beliefs with circumstance, he follows up that, "[naturalised epistemology] can be done by us only when we can make something of the variation of belief involved" $(1993,66)$, i.e. "make something of" captures the essence of naturalised modal epistemology. Since we cannot "make something of" absolutely necessary falsehoods, he concludes that any psychologically naturalistic explanation of why we absolutely modalise would/must fail. For the imaginative blocks that we face when we endeavour to give such an explanation are not contingent facts about us:

But it goes a little further, for in the light of what we have said, it will also be so that we cannot see the incapacity as just one we happen to be subject to; we cannot deem it a mere fact about ourselves, here, now (Blackburn 1993, 71; emphasis in original).

Thus, in clearer terms, psychologising why we absolutely modalise would/must fail because we cannot psychologise why we face the imaginative blocks that issue our judgments of absolute necessity: "We now find that if any natural explanation of our imaginative block can be given, this attacks our right to make the commitment" (Blackburn 1993, 71; emphasis in original).

To summarise: Our modal commitments enable us to vary our beliefs with circumstance via "make something of". We cannot do this for some beliefs and this inability renders the beliefs absolutely necessary. Consequently, the involved modal commitments must remain non-variable with circumstance, i.e. they must be impervious to naturalistic explanations. Thus, we cannot naturalistically explain why absolute necessities are absolutely necessary because to do so would mean they were not absolutely necessary in the first place, and if they ever were, they will therefrom cease to be absolutely necessary. Blackburn $(1993,72)$ puts it forcefully: "In the case of the modal, the phenomenon is antinaturalistic at its core".

Blackburn tells the story in a much more interesting manner and situates it within a much wider project, but this short rendition suffices for our purposes - namely, to show that naturalistically explaining why we absolutely modalise will not lead to the forfeiture of the involved necessity. To set us on our way, it would be best to clarify some aspects of Blackburn's argument which he is not so clear about.

\section{Taking stock of Blackburn's view of absolute necessity}

It is not clear to what degree we should read Blackburn on the antinaturalistic nature of absolute necessity. I, for one, tend to read him pessimistically - that he thinks we cannot naturalistically explain why we regard absolute necessities as absolutely necessary, come what may. But there seems to be room for a less pessimistic reading. For instance, he asks,

[o]r is this unduly pessimistic? Some relief might be got by teasing out more aspects of the core inability to "make anything of" a way of thought that accepts a putative impossibility. Obviously, there are enterprises of thinking through what modifications in logic are possible or what would be missing in a way of thought that consistently tried to make $1+1=3 \ldots$ So, it ought to be possible to hold both that these laws are necessarily true and that we can "make something of" ways of thought that lead people to deny them (Blackburn 1993, 72).

Regardless, I think this less-pessimistic reading ultimately reduces to my pessimistic reading. For no sooner had he moderated his pessimism, than he insisted that we hit a firmer imaginative block or forfeit the involved necessity: 
[The above quote] is not a serious obstacle to the direction of this essay. What we do is take a proposed deviation and follow it until either the way of thought seems possible and we no longer modalize against it - or it breaks down. But "breaks down" will mean: offends against something that we suppose essential to any scheme of thought (such as some distinction of truth and falsity...). Eventually we voice an inability to make anything of transgression against these norms: this is the surd that remains (Blackburn 1993, 72).

In short, it seems he wants us to read him pessimistically, even though he countenances that "it may do a little to moderate the antinaturalistic pessimism" (ibid.).

This then provides one way of reading his view that our inability to make anything of absolutely necessary falsehoods is not a contingent fact about us, which he is also not explicit about. Is the "inability" absolutely or relatively necessary? I think he needs it to be absolutely necessary. After all, were it relatively necessary, i.e. were there a given body of statements to which the inability follows as a consequence (see Hale 1996), it would be logically possible that we can make something of absolutely necessary falsehoods. So, since he wants to insist that we cannot make anything of them, come what may, then that inability must itself be absolutely necessary. But in what sense is it absolutely necessary? He does not say. I will zero in on this lacuna later below. For now, it suffices that I will read him in what follows as saying that our "inability" to make anything of absolutely necessary falsehoods is itself absolutely necessary.

From the foregoing, it is clear that Blackburn takes naturalistic explanations to be only psychological ones. But we now know that naturalistic explanations need not be psychological; they can also be linguistic and scientific (Nolan 2017a). Linguistic ones consider the behaviour of modal terms in our natural languages, while scientific ones look at the role modality plays in scientific theorisation. But a quasi-realist could insist that both explanations do not escape the challenge Blackburn raises. They would say a linguistic explanation presupposes making sense of the mental act involved in modalising, and since that mental act is "make something of", it reduces to a psychological one. Similarly, they would say explaining modality through understanding our best science entails regarding the world as such that we cannot make anything of false scientific claims independently of what anyone may think, i.e. we cannot give a psychological explanation of such an inability. So, in both instances, Blackburn's view stands. ${ }^{3}$ Notice how this insistence supports reading Blackburn pessimistically. For were linguistic and/or scientific explanations of why we absolutely modalise feasible, then absolute necessity would not be anti-naturalistic at its core after all.

This psychological dimension then explains why Blackburn takes quasi-realism as buttressing Quine's (1960) view about absolute necessity. Quine says we should abandon modalising in the absolute sense altogether, but Blackburn says we should at least know why we absolutely modalise before abandoning it. ${ }^{4}$ Zangwill (1988, 146; emphasis in original) argues that Blackburn seems to have missed Quine's point in that where he says absolutely necessary beliefs cannot be varied with circumstance, "Quine will say that all beliefs vary with circumstances, but some more than others". Perhaps this is why Hale $(1986,78)$ thinks Blackburn "confuses psychological facts about our sentiments with the "real modal status of propositions"". For Quine might just be saying that absolutely modalising is naturalistically explainable, albeit reductively. Even so, Blackburn seems to be saying that any such reductive naturalistic explanation would explain away the absoluteness of absolute modalising. Again, my pessimistic reading of him is fair.

Spelling out Blackburn's qualms with absolute necessity in this way helps to show where available responses fall short. Notably, Nichols (2006) argues that, pace Blackburn, we can give a psychologically naturalistic explanation for the imaginative blocks that issue judgments of absolute

3 Thanks to an anonymous reviewer for this journal for impressing this point upon me.

4 Since Quine famously takes epistemological questions to be psychological ones, his naturalism about epistemology is metaphysical (see n. 1). If so, then Blackburn, despite ruling that absolute necessity is antinaturalistic, is also metaphysically naturalistic about modal epistemology. However, as Nolan (2017a) clarifies, modal epistemology is best naturalised methodologically, and so, a case can be made against Blackburn in modal epistemology in a manner similar to Nolan's (2017b) case against him in meta-ethics. While this avenue is promising, I will not it pursue here. 
necessity, but his view falls short in one significant respect. It does not say anything about whether the judgments that it allows us to naturalistically explain lose their absoluteness. Let me quickly review his position then, to explain the gap he leaves open, which I want to fill here.

\section{Nichols on Blackburn's view of absolute necessity}

Nichols argues that Blackburn gives up too quickly. In his view, given what we now know about the neuropsychology of imagination, we can explain the imaginative blocks we face when we try to imagine how $1+1=3$ could be true. He writes that "pace Blackburn, a naturalist might be able to explain why we have an imaginative block against the proposition $1+1=3$ without being able to make anything out of thought that $1+1=3$ might be true" (Nichols 2006, 247). What explanation might this be?

In an earlier work (Nichols and Stich 2003), he argues that imagination is not an unconstrained fantasy generator, because imaginings and beliefs are in the "same code", i.e. they have the same contents, interact with the same cognitive mechanisms and have the same logical form. Consequently, he dubs this view, the "single code hypothesis" (Nichols 2004). The hypothesis is that "for any mechanism that takes input from both the [imagination] box and the belief box, the [imagination] representation $p$ will be processed much the same way as the belief representation $p$ " (Nichols 2004, 131).

Nichols (2006) then uses the single code hypothesis to explain why we face imaginative blocks when we attempt to consider how it is that $1+1=3$, for example. He gives this as the reason we face the blocks: "if the candidate belief that $p$ would be immediately rejected by the inference mechanisms, then the candidate [imagination] representation that $p$ will also be immediately rejected by the inference mechanisms" (Nichols 2006, 250). Thus, according to him, we face imaginative blocks when we endeavour to see how $1+1$ could be 3 , because of

the fact that the [imagination] representation that $p \& \sim p$ would engage our normal inferential systems. And just as our inferential systems would expel the belief representation $p \& \sim p$, so too do they expel the [imagination] representation that $p \& \sim p$ " (ibid.).

Simply, we face the blocks that issue judgments of absolute necessity because imagination is not an unconstrained fantasy generator in that it is hooked up to our inferential systems. Cognitivearchitectural constraints on imagination, therefore, explain why we face the blocks that issue judgments of absolute necessity.

Since this sort of explanation does not rely on us to make anything of absolutely necessary falsehoods, Nichols argues that, contrary to Blackburn, "make something of" does not capture the essence of naturalised modal epistemology, in that it is not characterised by varying beliefs with circumstance. Put differently, Nichols' view is that we are not obliged to understand the other side of the boundary, i.e. naturalistically explaining why $1+1 \neq 3$ is absolutely impossible does not necessarily involve understanding how it could be that $1+1=3$. He puts it better:

in pursuing a naturalistic explanation of the imaginative blocks, we are not obligated to "make sense" of propositions that are excluded by our imaginative blocks. We are merely obligated to explain how the blocks arise (Nichols 2006, 248; see also Björnsson 2004).

In this way, he argues that naturalised modal epistemology can be done for absolute necessities. I agree.

However, a quasi-realist could take Nichols' strategy to explain "make something of" away, as vindication that we cannot after all, in the manner that Blackburn explains, make anything of absolutely necessary falsehoods. Put differently, the quasi-realist could argue that despite having a naturalistic explanation for the imaginative blocks that issue the judgment that $1+1 \neq 3$ is absolutely impossible, we still cannot entertain a way of thought where $1+1=3$. Yes, Nichols has said we are not obliged to understand such a way of thought, that explaining how the blocks arise is what matters, but the quasi-realist could insist that an explanation of why the blocks arise is insufficient. They might say that we must at least be able to explain why our inferential systems rebel at contradictions, and that this would, in one way or other, involve understanding the other 
side of the boundary, which they would then say Blackburn has stressed we cannot do. For if we can, then we would understand whatever our inferential systems are blocking out, i.e. we would understand how a world where those blocked-out propositions are true looks.

I agree that we cannot do this. Although Nichols does not say, I suspect that he agrees as well - that is partly why he focuses on explaining how the blocks arise. At any rate, the gap he leaves open, which allows the quasi-realist to demand understanding what is being blocked out, is what I want to bridge here. The gap is that given what he says, it is unclear why we need not understand it. ${ }^{5}$ After all, it is one thing to respond to Blackburn's view that we cannot understand what is being blocked out by saying we need not understand it, and quite another to give the reason(s) why we need not understand it. In short, Nichols' view that we need not understand the other side of the boundary does not tell us whether our right to regard the involved judgments as absolutely necessary is secured or lost in not needing to understand the other side of the boundary.

My own view is that we will not lose any such right. My evidence is that we have had for a while now a naturalistic explanation for why "squaring the circle" is absolutely impossible, and neither have we lost nor we will ever lose our right to regard it as absolutely impossible just because we have the naturalistic explanation. In the next section, I will give this naturalistic explanation, and in the sixth section, I will explain why it has not led to us to losing our right to regard squaring the circle as absolutely impossible, thereby explaining why understanding the other side of the boundary does not matter.

\section{Squaring the circle: A case for naturalised absolute necessity}

To square a circle, one would have to use only a compass and straight edges, and construct for any given circle a square with the same area as the circle. Some quick clarifications before proceeding. First, it is not that a square of equal area with a circle does not exist. If a circle has a given area, then a square with sides that are each the root of that area has the same area as the circle. Second, it is not that giving the square of a circle is impossible, since it is possible in the above-described sense, but it is impossible under the restriction of using only a compass and straight edges. In this second sense, squaring the circle is absolutely impossible, although it is not absolutely impossible in the first sense. Thus, when I say "squaring the circle" in what follows, I mean it exclusively in the restricted second sense of using only a compass and straight edges.

Since the earliest days of mathematics, ${ }^{6}$ renowned mathematicians, like Anaxogoras, Euclid, Archimedes, Leonardo da Vinci, Descartes, to mention but a few, laboured in vain to square the circle. ${ }^{7}$ But we have had proof, since the late 19th century, that the task is absolutely impossible, thanks to the knowledge that $\pi$ is a transcendental number, i.e. that $\pi$ cannot be a root of any algebraic equation. The transcendence of $\pi$ proved monumental in deciding the absolute impossibility of squaring the circle, because how to determine whether a proposed Euclidean problem is possible has been established. For a proposed Euclidean problem to be possible, each of the data of the problem must be a root of one algebraic equation or other. In the case of squaring the circle, $\pi$ features as one of the data of the problem, and since $\pi$ cannot be a root of any algebraic equation, we know that the problem of squaring the circle cannot be determined by Euclidean constructions (Hobson

5 Nichols uses chimpanzees' cognitive boundedness as an analogy, saying that "when we do the parallel naturalistic project on humans, we're the apes under investigation, and we should try, as far as possible, to achieve a similar distance" $(2006,248)$. The quasi-realist might pick on this, arguing that given this analogy, the reason we need not understand the other side of the boundary is as Blackburn says - that we cannot. That is, Nichols is saying that only an external observer can investigate whatever aspect of our psychology subserves absolute modalising just as cognitive ethologists do for chimpanzees. But the quasi-realist should be careful here. Nichols clearly says that "when we do the parallel naturalistic project on humans" (2006, 248; emphasis added), meaning that we are both the investigator and the investigated. Moreover, neuroscience has evolved to such an extent that we now know what we did not know, hence, Nichols saying that "Blackburn surrenders too quickly" (2006, 247; emphasis added). What neuroscience tells us about our psychology vis-á-vis absolute modalising is what Nichols laid out, which though it entails that we need not understand the other side of the boundary, excludes why we need not have the understanding. The last part is what I hope to add to below.

6 One source (Hobson 1913) traces the first appearance of the problem to the Rhind Mathematical Papyrus (ca. 1650 BC).

7 See Fletcher (2007) for a review of the different approaches used over the years for trying to square a circle. 
1913). Ergo, squaring the circle is absolutely impossible. It is both nomically and logically (or more precisely, mathematically) impossible that circles can be squared. ${ }^{8}$

Though very brief, this exposition of why squaring the circle is absolutely impossible is apt for our purpose, since it counts, in all relevant senses, as an example that Blackburn should not have any problem accepting as a case of absolute necessity. As we have seen above, only mathematics and logic cases are an absolute necessity for him, and what make squaring the circle absolutely impossible are the mathematical principles that it entails, not that it is a Herculean task that requires superhuman strength and dexterity to be accomplished. ${ }^{9}$ Regardless of strength, dexterity and creativity, no one can square a circle: it is pointless for anyone to try.

However, despite this explanation for why squaring the circle is absolutely impossible, a quasi-realist might counter that the explanation does not rely on any facts about our psychology, and so, it does not count as a psychologically naturalistic explanation. But should they make this move, they would be adopting an outdated psychology of mathematical cognition, saying that the only way an epistemology of mathematics can be psychological is for it to rely on some phylogenetic or ontogenetic facts about our psychology, and this is no longer the accepted psychological explanation of mathematical cognition.

Initially, psychological research about mathematics focuses on neuroscientific issues involved in the mathematically relevant behaviour of an individual, i.e. they were elucidated at the individual level: "The typical view in cognitive science is that mathematical cognition should be studied as a purely individual achievement" (Hohol and Miłkowski 2019, 2; emphasis added). But this approach has been questioned (e.g. Hutchins 1995). Mathematics seems not to be the achievement of any single individual; rather,

mathematical justificatory practices may be understood in terms of repeatable public procedures that rely on the capacities of cognitive agents to jointly construct, explore and reconfigure representational tokens (Hohol and Miłkowski 2019, 2).

That is, mathematical practice is shared by individuals who can publicly use the same cognitive artifacts. Where "cognitive artifacts" are entities that "maintain, display, or operate upon information in order to serve a representational function and that affect human cognitive performance" (Norman 1991, 17).

Cognitive artifacts that were pivotal in the evolution of mathematical reasoning include diagrams and linguistic formulae (Netz 2003), cognitive metaphors (Núñez and Lakoff 2005), basic spatial capacity (Spelke et al. 2010), and so on. ${ }^{10}$ These artifacts enhanced the performance of groups of individuals over time, such that their collective performance and not just the distributed individualistic ones became reified in our evolutionary history, perhaps through the Baldwin effect. ${ }^{11}$ After all, it is one of our distinctive characteristics that we are able to modify our environment through the creation of artifacts and transmit the modifications to subsequent generations (Clark 2004). One effect of this transformative process is the availability of "a new kind of cognitive niche whose features and properties complement but do not need to replicate the basic modes of operation and representation of the biological brain" (Clark 2006, 370-371). In this way, highly intellectual endeavours like mathematics are now said to not be the achievement of any single individual.

For instance, even though the transcendence of $\pi$ was proved by Ferdinand von Lindemann in 1882, it would be myopic to say it was solely his achievement. Had Joseph Liouville not earlier proved that there could be transcendental numbers in 1844, and had Charles Hermite not proved that

8 But not epistemically impossible. See, however, the sixth section for why epistemic possibility does not count.

9 Compare the inscription of a heptadecagon (a 17-sided polygon) in a circle. It is seemingly a more difficult task than the inscription of a square (a 4-sided polygon) in a circle, but it has been shown to be constructible by Gauss in 1796, way before the latter was proved to be absolutely impossible. The reason the former is not only logically but also nomically possible (i.e. constructible using only compass and straight edges) is that $\pi$ does not feature as one of its data. Otherwise put, in both cases, the challenge is not about the nature of the tasks, but about the mathematical principles underlying them.

10 See Heersmink (2013) for a taxonomy of cognitive artifacts.

11 The Baldwin effect is an evolutionary mechanism which transforms a culturally invented and acquired trait into an instinctive trait by means of natural selection. See Baldwin (1896) for an etymology, and Godfrey-Smith (2003) for a development. 
$e$ is a transcendental number in 1873, it is highly doubtful that von Lindemann would have been able to prove the transcendence of $\pi$. What is more, it is now agreed in most quarters within cognitive science and evolutionary psychology that individual achievements, like those of Liouville, Hermite, and von Lindemann, would have been unachievable without reliance on some cognitive artifacts. Clark (2004, 34; emphasis added) summarises this point best:

The project of understanding human thought and reason is easily misconstrued...as the project of understanding what is special about the human brain [rather it] requires an even broader perspective: one that targets multiple brains and bodies operating in specially constructed environments replete with artifacts.

Consequently, mathematical cognition (Tylén et al. 2014) and cognition in general (Gureckis and Goldstone 2006) are no longer understood in terms of individual achievements. Cognitive study of mathematical cognition outstrips facts about the psychology of individuals engaged in mathematical practice, including artifacts that have structured the cognitive niche in which the practice thrives.

Under this extended sense, the given explanation for why squaring the circle is absolutely impossible counts as psychological in all relevant senses. It may not rely on any phylogenetic or ontogenetic facts about our psychology, but it certainly relies on some cognitive artifacts that have constrained the construction of the cognitive niche for mathematical practice. If so, then we can explain, using psychological facts about us, in the extended sense of cognitive artifacts, why squaring the circle is absolutely impossible. Importantly, no one who understands the explanation now claims as a result of having the understanding that squaring the circle has become contingent for them.

The quasi-realist might object, however, demanding clarification about the modal force of Euclidean axioms qua part of the explanans for why squaring the circle is judged to be absolutely impossible. If it is absolutely necessary - as expected - then I have only pushed Blackburn's concern one step back - to the level of saying we cannot naturalistically explain why we take Euclidean axioms to be absolutely necessary. If they do not have modal force at all, then they cannot be part of the explanans. These are Blackburn's qualms with truth-conditional analyses of modality, to which Scott Shalkowski (2008) has given a clear response. According to him, both horns of Blackburn's dilemma are misdirected toward conceptual analysis, but he clarifies that not all truth-conditional analyses of modality aim to analyse modal concepts. Some take modal concepts as primitive, i.e. concepts for which there are no non-modal equivalents, and for those truth-conditional analyses of modality, both horns of Blackburn's dilemma fail.

The details of Shalkowski's (2008) arguments are not important for our purpose; what is is his conclusion: Euclidean axioms are primitive concepts, and so, despite their absolutely necessary modal status, there are no non-geometrical, a fortiori, non-modal equivalents. Thus, their absolutely necessary modal status does not fall prey to the first horn of Blackburn's dilemma, and so there is no residual challenge.

However, even though this blocks the quasi-realist from saying Euclidean axioms cannot be part of the explanans for why we judge squaring the circle to be absolutely impossible, it leaves open the caveat that, having now admitted Euclidean axioms as (part of) a psychological explanation in the extended sense of cognitive artifacts, we can now vary the judgment with circumstance, i.e. imagine differently. For example, the quasi-realist could say we can now utter this counterfactual:

$C$ : Had $\pi$ been countable and rational, we would have been able to square the circle.

Simply, $C$ captures an imaginable scenario where squaring the circle is logically possible, even though it is nomically impossible. Otherwise put, they may agree that we can explain why we regard squaring the circle as absolutely impossible - as I have done here - but add that once we admit the offered explanation as naturalistic, we lose our right to regard squaring the circle as absolutely impossible. I disagree.

To make my case, the argumentative framework would have to differ from what has come before - from psychological to meta-psychological. For whether $C$ renders squaring the circle logically possible as the quasi-realist claims turns on how the notion of "absolute necessity" is being used in 
quasi-realism. This is not only because there are different conceptions of absolute necessity, but also because what it takes for each conception to succeed/fail such that a proposition/judgment becomes logically possible differs. I will argue that available conceptions of absolute necessity do not work for $C$.

\section{On the use of absolute necessity in quasi-realism}

The quasi-realist says $C$ captures an imaginable scenario where squaring the circle is logically possible. But why "logically", it might be asked? Simple: because nomic possibility is ruled out since no one can square a circle, and epistemic possibility, though not ruled out, trivialises things, since the opposite of just about any plausible absolute necessity may be epistemically possible, i.e. true for all we know. This leaves only logical possibility. Hence, Zangwill (1988, 145; emphasis added) says that "Blackburn's idea is that when we can 'make something of', explain or understand someone's not believing a true proposition, then we put it down as logically contingent". Thus, for the quasi-realist to say that $C$ renders squaring the circle possible, i.e. for them to insist that it is absolutely necessary that we cannot "make something of" absolutely necessary falsehoods, $C$ must render squaring the circle logically possible.

But if so, then the quasi-realist would be saying that absolute necessities are absolutely necessary only to the extent to which our cognitive makeup is necessary. They want to insist that we cannot make anything of absolutely necessary falsehoods come what may. But if our cognitive makeup is not necessary in some determinate albeit non-absolute sense, then the "come what may" qualification drops out, but we have seen above that it must not. This then explains why the quasi-realist could demand an explanation of why our inferential systems rebel at contradictions from Nichols. For, according to the quasi-realist, once we can see why our inferential systems so rebel, we lose our right to regard the involved modal judgments as absolutely necessary, i.e. we explain away the necessity of our cognitive makeup, and with it, the necessity of the modal judgments.

If we call the necessity of our cognitive makeup "psychological necessity", then the quasi-realist is saying that absolute necessity is "at least as strong as" psychological necessity. Where " $\square 1$ is at least as strong as $\square 2$ if... ' $\square 1 p$ ' always entails " $\square 2 p$ "” (Hale 1996, 94). The quasi-realist is saying that the psychological necessity of our inability to "make something of" absolutely necessary falsehoods always entails the absolute necessity of absolute necessities. More to the point, and it bears repeating, once we explain away this psychological necessity, which the quasi-realist is saying my argument inadvertently does, absolute necessities cease to be absolutely necessary: they become logically possible. Hence, $C$.

This way of understanding "absolute necessity" corresponds to Hale's (2012) "maximalabsoluteness" conception of absolute necessity. He explains that a proposition $p$ is maximalabsolutely necessary if "it implies, and so is at least as strong as, any other comparable kind of necessity" (Hale 2012, 121). Thus, the quasi-realist means to say that our inability to make anything of absolutely necessary falsehoods is maximal-absolutely necessary. This, for me, is the conception of absolute necessity at work in quasi-realism, which Blackburn does not specify, and which I promised that I will specify. But maximal-absoluteness does not afford any room for $C$ to render squaring the circle logically possible. Before showing why, let us acknowledge that the quasi-realist may deny that maximal-absoluteness is the conception of absolute necessity at work in quasi-realism.

Hale also gives two other conceptions of absolute necessity: limit-absoluteness and general counterfactual-absoluteness. A proposition $p$ is limit-absolutely necessary if $p$ is necessary relative to a set of propositions $\Phi$, no matter the $\Phi$ we choose. A proposition $p$ is general counterfactualabsolutely necessary if $p$ would be the case, no matter what else was the case. Thus, the quasi-realist might say that the conception of absolute necessity at work in quasi-realism is not maximalabsoluteness, but one of these other alternatives. This is fine, but it really does not matter whether they are right, or I am, for as we will see in what follows, all three conceptions of absolute necessity do not help their case. First, limit-absoluteness.

Even though Blackburn says the absoluteness of absolute necessities partly consists in our inability to understand the other side of the boundary, I suspect that the quasi-realist would not 
want to say limit-absoluteness is the conception of absolute necessity at work in quasi-realism. For under it, understanding the other side of the boundary becomes irrelevant: squaring the circle might still be absolutely impossible whether we choose how our cognitive makeup actually is, or how it would be were $C$ true. This way, we have a first working theory for why Nichols (2006, 248 ) is right to say that "we are not obligated to make sense of propositions that are excluded by our imaginative blocks, that an explanation of how the block arises is sufficient": it simply does not matter whether we can make sense of the blocked-out propositions. Some absolute necessities would remain absolutely necessary even if we come to understand the other side of the boundary, and we cannot decide upfront that squaring the circle is not part of this category. Limit-absoluteness does not help the quasi-realist's case.

Second, the reason I began with limit-absoluteness is that it shares a feature with maximalabsoluteness, which explains why maximal-absoluteness also cannot help the quasi-realist's case, but this feature might be obscured if we were not already familiar with limit-absoluteness. What feature? Hale (2012, 124; emphasis in original) answers: "limit-absolute and maximal-absolute necessities are always logical - i.e. there can be no non-logical absolute necessities in either of these senses of "absolute". Thus, if I am right that the conception of absolute necessity at work in quasi-realism is maximal-absoluteness, then our inability to make anything of absolutely necessary falsehoods is already logically necessary. If so, and since "any kind of alethic possibility...conforms to a form of the law of noncontradiction" (Hale 2012, 122), then $C$ cannot now render squaring the circle logically possible, since squaring the circle is already logically impossible, given maximalabsoluteness. ${ }^{12}$ It cannot be both logically possible and impossible that circles can be squared. If so, then both limit- and maximal-absoluteness cannot work for the quasi-realist's agenda. A second working theory for why need not understand the other side of the boundary is then that the quasi-realist cannot justify why we should: the demand is self-contradictory.

Third, the quasi-realist might respond that the conception of absolute necessity at work in quasi-realism is rather general counterfactual-absoluteness. For, since the reason squaring the circle is absolutely impossible is the mathematical principles underlying it, squaring the circle is more appropriately an arithmetical necessity, which may be metaphysical not logical. ${ }^{13}$ Following Hale $(2012,124)$, who says, "[s]ince I think it is very plausible that there are non-logical absolute necessities - for example, arithmetical ones - I think this is a quite strong reason to prefer the generalised counterfactual explanation of absoluteness", the quasi-realist would then say the conception of absolute necessity at work in quasi-realism is rather general counterfactualabsoluteness. Fair enough, but if they say this, then they run into a brick wall, for under general counterfactual-absoluteness, $C$ - the counterfactual that "had $\pi$ been countable and rational, we would have been able to square the circle" - uncontroversially cannot render squaring the circle logically possible.

This is because, given general counterfactual-absoluteness, it would be the case that squaring the circle is absolutely impossible no matter what else was the case, i.e. no matter what else was logically, nomically and metaphysically possible, i.e. no matter what else was possible in any alethic sense. ${ }^{14}$ The quasi-realist should distance themself from general counterfactual-absoluteness if they want $C$ to stand any chance of rendering squaring the circle logically possible. A third working theory then for why we need not understand the other side of the boundary is just that understanding it would not change a thing.

12 I have silenced a premise here, according to which a judgment can only issue an absolute necessity of its own sort. Hale (1996, 93) puts it better: "Evidently...the members of $\Phi$ themselves will automatically qualify as ø-necessary". That is, if the judgment that issues a necessity is maximal-absolutely necessary, then the necessities it issues will also be maximal-absolutely necessary. So, if our inability to make anything of absolute necessities is maximal-absolutely necessary, then the necessities the inability issues are already maximal-absolutely necessary. Since maximal-absolute necessities are always logical, then the necessities issued by the inability are logical necessities. Hence, squaring the circle is already logically impossible if our inability to make anything of it is maximal-absolutely necessary. Mutatis mutandis if the judgment is limit-absolutely or general-counterfactually necessary.

13 It is not clear which preceded the other between logical and metaphysical necessities. Hale (2012) thinks logical necessities precede metaphysical ones. But, see Shalkowski (2004) for why and how metaphysical necessities precede logical ones. What I say goes through whichever side of this debate is correct.

14 Alethic modalities are the modalities of truth, and Blackburn is only concerned with alethic modalities. 
If so, then we are back to a point I made earlier that it really does not matter who is right between me and the quasi-realist concerning the conception of absolute necessity at work in quasi-realism. Either I am right, and the conception is maximal-absoluteness, or the quasi-realist is right, and it is limit-absoluteness or general counterfactual-absoluteness. In both cases, we have seen that squaring the circle does not come out logically possible. If so, then all three conceptions of absolute necessity cannot help the quasi-realist capture how $C$ renders squaring the circle logically possible. However, if, as I said at the beginning of this section, logical possibility is the only sense of possibility available to the quasi-realist, then my argument stands: squaring the circle remains absolutely impossible even though we can now naturalistically explain why we regard it as absolutely impossible. More importantly, we continue to regard it as such despite the failure of $C$.

The problem, as it must have already become clear, is that quasi-realism cannot escape being couched in modal terms, as evident in its reliance on "absolute necessity", which Blackburn does not specify. But once specified, as I have done here, quasi-realism becomes problematic. Hale $(1986,79)$ puts it better:

[Quasi-realism] is, and probably has to be, specified in modal terms (can/can't imagine...). If the possibility referred to here is logical, the theory is circular. If not, of what sort is it? Declaring it to be psychological would avoid direct circularity but threatens to square ill with the hinted normativeness ("our best attitude of comprehension or imagination"). This difficulty is further aggravated if a [quasi-realist] account of non-logical modalities is to be given. Indeed, one wonders whether the [quasi-realist] will be able to preserve the distinctions many of us think we discern between logical and natural or physical necessity, etc. (see also O'Connor 2008). ${ }^{15}$

Thus, here is the bridge I have constructed to cover the gap that Nichols leaves open. It is not just that the we should not worry about our inability to understand the other side of the boundary because we need not be able to understand it as he says, but that we should not worry about understanding it because were we to come to understand it, things would not change, given limit-absoluteness, maximal-absoluteness, and general counterfactual-absoluteness. ${ }^{16}$

If so, then the demand that we understand the other side of the boundary loses its dispositive force, since its whole point is to show that once we do, the involved modal commitments become logically possible, and so, no longer absolutely necessary/impossible. But if we cannot make much sense of what the quasi-realist means by "the commitments becoming logically possible" and "our inability to make anything of absolute necessity is absolutely necessary", then why should we be held ransom by the demand? And even when we try to make some sense of what the statements might mean, as I have done here, we end up with a view that understanding the other side is not as important as the quasi-realist makes it out to be.

\section{Conclusion}

I agree with Blackburn that we cannot make anything of absolutely necessary falsehoods in the sense that we cannot understand the other side of the boundary. I also agree with Nichols that naturalised modal epistemology is not equal to "make something of" in the sense that we need not be able to understand the other side of the boundary. But, unlike Nichols who left it open whether we lose our right to regard absolute necessities as absolutely necessary once we can naturalistically explain why

15 Plus, as Hale explains, quasi-realism seems unformalisable into purely logical vocabularies, and as we know, it is virtuous for a theory to be simple and elegant. According to him, if $[\square(2+2=4)]$ is the formalised version of the sentence, "we cannot imagine how things would be were $2+2 \neq 4$ ", then what should we say about $\square[\square(2+2=4)]$ ? What can we not imagine in this case? Is it that "we cannot imagine our inability to imagine how things would be were $2+2 \neq 4$ "? If yes, and I see no other option, then there is a problem. I can, and in fact, I am imagining as I write, that I cannot imagine how things would be were $2+2 \neq 4$. Thus, Hale $(1986,78)$ concludes that the whole formalisation "should be ill-formed" (see also Dicken 2010). I agree. While this is separate from the content of quasi-realism vis-à-vis absolute necessity, it captures some of its lurking flaws.

16 There is at least one conception of absolute necessity I have not considered here - the Kantian-based existence conception, according to which "[a]n absolutely necessary proposition is a proposition whose negation cancels all possibility" (Stang 2016, 127). I set it aside because even the quasi-realist would agree that whether or not we can naturalistically explain why we absolutely modalise does not add or remove from the set of all possibility. 
they are absolutely necessary, a gap that makes his view fall short of responding satisfactorily to Blackburn, I have shown that we do not lose any such right.

Despite having a naturalistic explanation for why we regard squaring the circle as absolutely impossible without having to "make something of" a world where $\pi$ is countable and rational, we do not lose our right to regard squaring the circle as absolutely impossible. Importantly, we now know why we do not lose this right: squaring the circle does not come out logically possible no matter how we characterise the absolute necessity of our inability to "make something of" a world where $\pi$ is countable and rational.

It might do better, however, to moderate the achievement of this article, in that I have only offered one case where the psychological explanation that we have for why we hold a certain judgment as absolutely necessary does not threaten the absoluteness of the involved necessity. Fair enough - we do not as yet have similar explanations for many other judgments we take to be absolutely necessary. But if what I have said here is any indication, then we can expect that if and when we do have psychological explanations for our judgments of those other absolute necessities, that the explanations will not come with a forfeiture of the absoluteness of the involved necessity. If so, then, following Nichols, we can say convincingly that naturalising modal epistemology will not leave out absolute necessity. ${ }^{17}$

\section{ORCID iD}

Michael Omoge - http://orcid.org/0000-0002-6010-4093

\section{References}

Baldwin, J. 1896. "A New Factor in Evolution." American Naturalist 30(354): 441-451. doi:10.1086/276408

Björnsson, G. 2004. “A Naturalist's Approach to Modal Intuitions.” In Modal Epistemology, edited by E. Weber and T. De Mey, 1-24. Brussels: Royal Flemish Academy of Belgium.

Blackburn, S. 1984. Spreading the Word. Oxford: Oxford University Press.

Blackburn, S. 1993. Essays in Quasi-realism. Oxford: Oxford University Press.

Clark, A. 2004. "Towards a Science of the Biotechnological Mind." In Cognition and Technology: Coexistence, Convergence, and Co-evolution, edited by B. Gorayska and J. Mey, 25-36. John Benjamins Publishing Company. doi:10.1075/z.127.03cla

Clark, A. 2006. "Language, Embodiment, and the Cognitive Niche." Trends in Cognitive Sciences 10(8): 370-374. doi:10.1016/j.tics.2006.06.012

Clarke-Doane, J. 2019. "Metaphysical and Absolute Possibility." Synthese 198(S8): 1861-1872. doi:10.1007/s11229-019-02093-0

Fletcher, R. 2007. "Squaring the Circle: Marriage of Heaven and Earth." Nexus Network Journal 9(1): 119-144. doi:10.1007/s00004-006-0033-7

Dicken, P. 2010. Constructive Empiricism. London: Palgrave Macmillan. doi:10.1057/9780230281820

Godfrey-Smith, P. 2003. "Between Baldwin Scepticism and Baldwin Boosterism." In Evolution and Learning: The Baldwin Effect Reconsidered, edited by B. H. Weber and D. J. Depew, 53-67. Cambridge, Massachusetts: MIT Press.

Gureckis, T., and R. Goldstone. 2006. "Thinking in Groups.” Pragmatics \& Cognition 14(2): 293-311. doi:10.1075/pc.14.2.10gur

Hale, B. 1986. “The Compleat Projectivist.” Philosophical Quarterly 36(142): 65-84.

Hale, B. 1996. “Absolute Necessities.” Philosophical Perspectives 10: 93-117.

Hale, B. 2012. "What is Absolute Necessity?” Philosophy of Science 16(2): 117-148.

17 An earlier version of this article was presented at an invited talk at Stellenbosch University. I thank the audience of that talk for their insightful questions. I especially thank Oritsegbubemi Oyowe, David Mertens, Monique Whitaker, David Spurrett, Peter Godfrey-Smith, Jessica Leech, Nick Zangwill and Daniel Nolan for reading earlier versions of this article and for their valuable comments, without which many aspects of the article would have remained very obscure and impenetrable. 
Heersmink, R. 2013. “A Taxonomy of Cognitive Artifacts: Function, Information, and Categories." Review of Philosophy and Psychology 4(3): 465-481. doi:10.1007/s13164-013-0148-1

Hobson, E. 1913. "Squaring the Circle": A History of the Problem. Cambridge: Cambridge University Press.

Hohol, M., and M. Miłkowski. 2019. "Cognitive Artifacts for Geometric Reasoning." Foundations of Science 24(4): 657-680. doi:10.1007/s10699-019-09603-w

Hutchins, E. 1995. Cognition in the Wild. Cambridge, Massachusetts: MIT Press.

Macarthur, D., and H. Price. 2007. "Pragmatism, Quasi-realism and the Global Challenge." In The New Pragmatists, edited by C. Misak, 91-121. Oxford: Oxford University Press.

Netz, R. 2003. The Shaping of Deduction in Greek Mathematics: A Study in Cognitive History. Cambridge: Cambridge University Press.

Nichols, S. 2004. "Imagining and Believing: The Proomise of a Single Code." Journal of Aesthetics and Art Criticism 62(2): 129-139. doi:10.1111/j.1540-594X.2004.00146.x

Nichols, S. 2006. "Imaginative Blocks and Impossibility: An Essay in Modal Psychology." In The Architecture of the Imagination, edited by S. Nichols, 237-256. Oxford: Oxford University Press. doi:10.1093/acprof:oso/9780199275731.003.0012

Nichols, S., and S. Stich. 2003. Mindreading. Oxford: Oxford University Press. doi:10.1093/0198236107.001.0001

Nolan, D. 2017a. "Naturalized Modal Epistemology." In Modal Epistemology after Rationalism, edited by B. Fischer and F. Leon, 7-28. Cham: Springer.

Nolan, D. 2017b. "Methodological Naturalism in Metaethics." In The Routledge Handbook of Metaethics, edited by T. McPherson and D. Plunkett, 659-673. Routledge. doi:10.4324/9781315213217-43

Norman, D. 1991. “Cognitive Artifacts." In Designing Interaction: Psychology at the Human-computer Interface, edited by J. Carroll, 17-38. Cambridge: Cambridge University Press.

Núñez, R., and G. Lakoff. 2005. "The Cognitive Foundations of Mathematics: The Role of Conceptual Metaphor." In The Handbook of Mathematical Cognition, edited by J. I. D. Campbell, 109-124. New York: Psychology Press.

O'Connor, T. 2008. Theism and Ultimate Explanation. Hoboken: Blackwell Publishing Ltd. doi: $10.1002 / 9781444345490$

Omoge, M. 2021. "Imagination, Metaphysical Modality, and Modal Psychology." In Epistemic Uses of Imagination, edited by C. Badura and A. Kind, 79-99. New York: Routledge.

Papineau, D. 2009. "The Poverty of Analysis." Proceedings of the Aristotelian Society, Supplementary Volumes 83 (1): 1-30. doi:10.1111/j.1467-8349.2009.00170.x

Quine, W. 1960. Words and Objects. New York: John Wiley and Sons.

Quine, W. 1969. Ontological Relativity and Other Essays. New York: Columbia University Press.

Shalkowski, S. 2004. "Logic and Absolute Necessity." Journal of Philosophy 101(2): 55-82. doi:10.5840/jphil200410128

Shalkowski, S. 2008. "Blackburn's Rejection of Modals.” Philosophy of Science 12(1): 93-106.

Spelke, E., S. Lee, and V. Izard. 2010. "Beyond Core Knowledge: Natural Geometry." Cognitive Science 34(5): 863-884. doi:10.1111/j.1551-6709.2010.01110.x

Stang, N. 2016. Kant's Modal Metaphysics. Oxford: Oxford University Press. doi:10.1093/acprof: oso/9780198712626.001.0001

Tylén, K., R. Fusaroli, J. Bjørndahl, J. Rączaszek-Leonardi, S. Østergaard, and F. Stjernfelt. 2014. "Diagrammatic Reasoning: Abstraction, Interaction, and Insight." Pragmatics \& Cognition 22(2): 264-283. doi:10.1075/pc.22.2.06tyl

Zangwill, N. 1988. "Fact, Science, and Morality: Essays on A. J. Ayer's Language, Truth, and Reality." Analytic Philosophy 29(3): 145-148. 